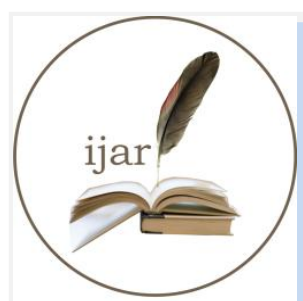

ISSN NO. 2320-5407
Journal Homepage: $-\underline{w w}$.journalijar.com
INTERNATIONAL JOURNAL OF
ADVANCED RESEARCH (IJAR)

Article DOI: $10.21474 /$ IJAR01/8431

DOI URL: http://dx.doi.org/10.21474/IJAR01/8431
INTERNATIONAL JOURNAL OF ADVANCED RESEARCH (JJAR)

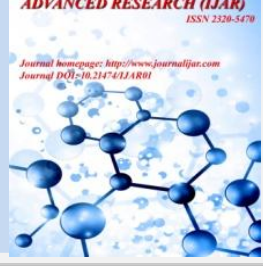

RESEARCH ARTICLE

\title{
A THORACIC COMPLICATION OF ENDO-BARIATRIC INTRA-GASTRIC BALLOON INSERTION CASE REPORT.
}

\section{Yasser Aljehani $^{1}$, Norah Alayyaf ${ }^{1}$ and Ahmed Al-Marhabi ${ }^{2}$.}

1. Division Of Thoracic Surgery, Department Of Surgery, King Fahd Hospital Of The University, College of Medicine, Imam Abdulrahman Bin Faisal University.

2. Gastroenterology Unit, Internal Medicine Department, King Fahd Hospital Of The University, College of Medicine, Imam Abdulrahman Bin Faisal University. Dammam, Saudi Arabia.

\section{Manuscript Info}

Manuscript History

Received: 18 November 2018

Final Accepted: 20 December 2018

Published: January 2019

Key words:-

Endo-bariatric, Esophageal perforation, Intragastric balloon, Obesity.

\section{Abstract}

Obesity has become a burden on healthcare systems. This has led to influx of variety of modalities to treat it. The endo-bariatric arm of management has expanded considering it less invasive nature. As a consequence, new kind of complications have been reported. We report a rare thoracic complication of endo-bariatric procedure that was treated with successful result. The report highlights the nature of the complication and the way to approach it.

Copy Right, IJAR, 2018,. All rights reserved.

\section{Introduction:-}

Intra-gastric balloon (IGB) insertion is a known trend in noninvasive, or what is so called endo-bariatric surgery [1]. It is made of silicone placed endoscopically in the stomach then filled with saline to induced a satiety feeling that helps in losing weight temporarily. Many studies show promising results of weight loss [2, $\underline{3}]$. Although side effects were reported including perforation of the gastrointestinal tract, but it was mainly in the stomach or distal to that. Such serious complications need immediate attention and management. To our knowledge this is the rarest thoracic complication reported.

\section{The Case:}

A 41 years old female with a body mass index of 34 and not known to have any chronic medical illness who came to our institution with abdominal pain, shortness of breath and fever for few days. Her past history revealed two endoscopic gastric balloon insertion in another hospital in the same session. The initial first balloon insertion was difficult with severe pain the resulted in deflation of the balloon and left it to pass by defecation. In the same setting they insert another balloon directly into the stomach, According to the report. The patient was admitted to ICU for 10 days with conservative treatment, pigtail to drain the left pleural space and antibiotics. She was discharged after that and a few days later developed generalized malaise, fever, shortness of breath and chest pain. She went back to the same hospital and underwent yet another endoscopy for retrieval of the balloon, which was done as she was informed. Few days later she presented to our hospital with the aforementioned complaints. Her Chest X Ray (CXR) showed a obliteration of left costophrenic angle with possible fluid collection and rounded foreign body (gastric balloon) in the left pleural cavity (figure 1). A chest computed tomography (CT) scan confirmed the diagnosis (figure 2). She underwent left thoracotomy; decortication of the $3^{\text {rd }}$ stage empyema thoracis with the removal of the gastric balloon (figure 3). A Pleural flap was used to cover the esophageal perforation that was found. Drainage tubes were inserted as usual and two days later an esophageal stent was inserted endoscopically since it was not

Corresponding Author:-Yasser Aljehani.

Address:- Division Of Thoracic Surgery, Department Of Surgery, King Fahd Hospital Of The 
available during the operative exploration. The patient did well clinically and was discharged in good condition. The stent was removed after 8 weeks and her follow up after a year showed resolution of her condition. She got pregnant and delivered a healthy child after another year of follow up.

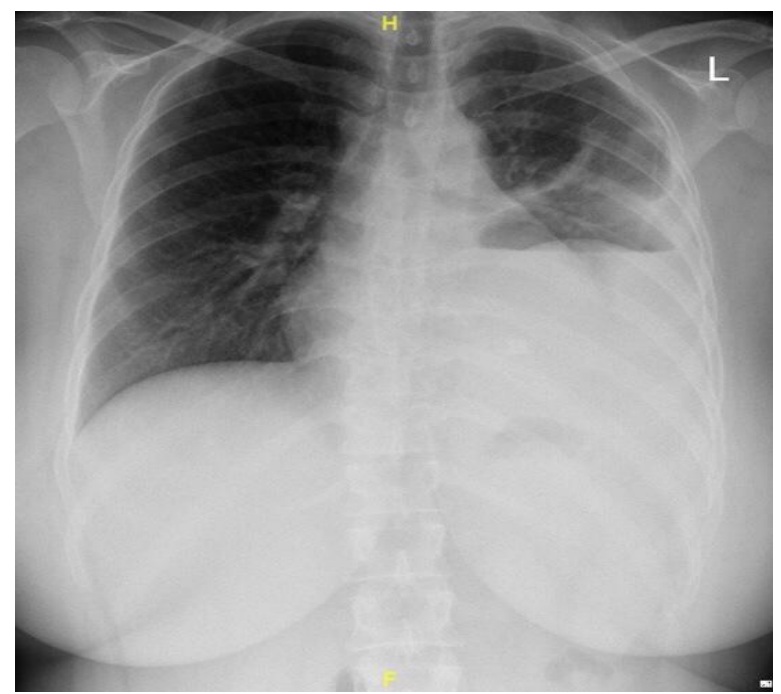

Fig 1:-CXR - Pre operative: Initial CXR at presentation to ER, showing obliterated left costophrenic angle and radio-opaque shadow of the retained intra-gastric balloon in the pleural space.

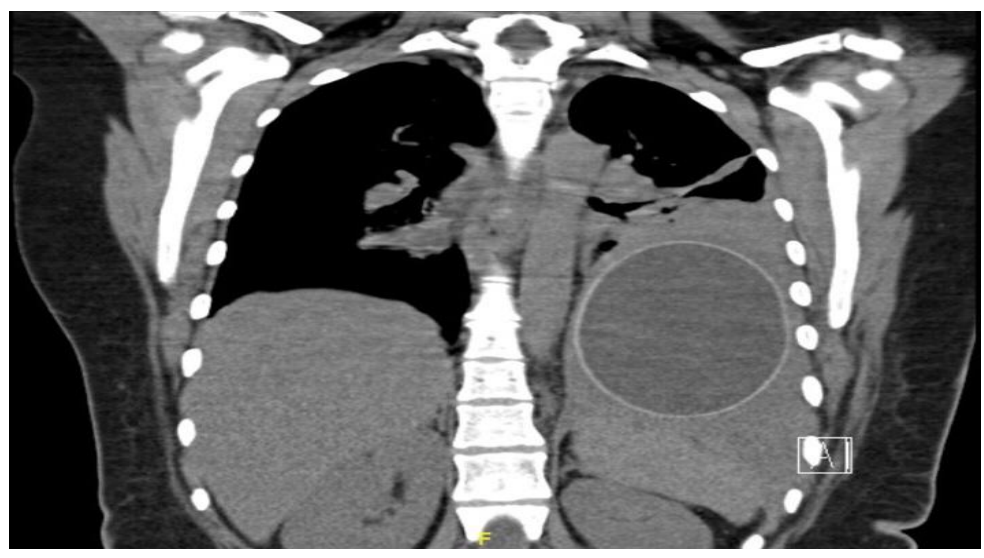

Fig 2:-Chest CT scan confirming the presence of an inflated and retained intra-gastric balloon in the left pleural space, most likely in the sub-pulmonic space.

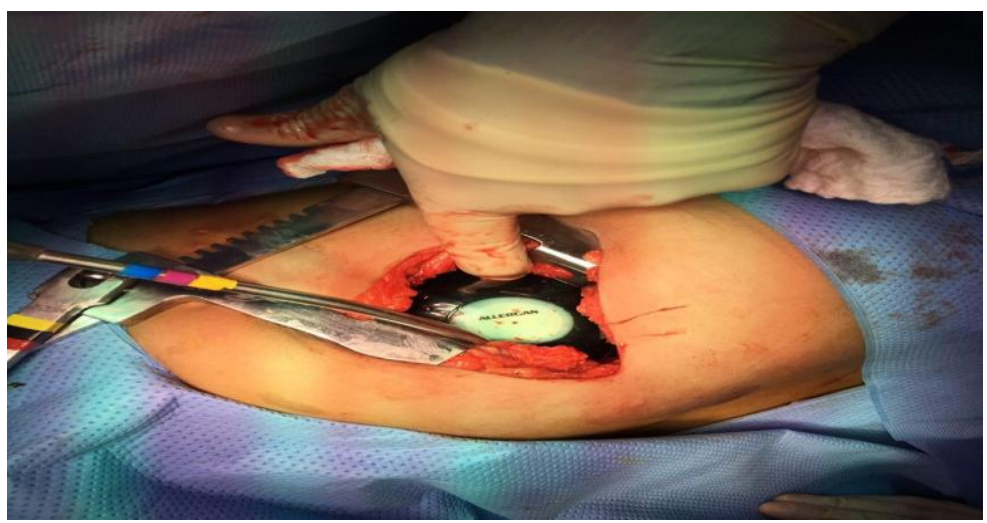

Fig 3:-Operative picture at the time of retrieving the balloon from the thoracotomy incision. 


\section{Discussion:-}

Obesity is a major public health burden around the world, the prevalence of overweight and obesity in Saudi Arabia has become the highest even among children [4]. It is associated with comorbidities such as diabetes mellitus type II, hypertension, dyslipidemia, coronary artery disease, stroke or cancer [5]. The treatment of obesity is multidisciplinary approach including modified lifestyle, pharmacological and for long term effectiveness the bariatric surgery which became as an effective choice. This includes; adjustable gastric banding, gastric bypass, biliopancreatic diversion and endo-bariatric procedures such as intragastric balloon insertion []]. The latter is considered less invasive procedure that consists of a silicone balloon and valve that is filled with sterile saline or methylene blue dye to detect any deflation early [7]. Coloring the patient's urine is an indication of leak or balloon perforation [7]. The IGB is safe, nevertheless, variable degrees of complications have been reported [ $\underline{8}$ ]. The most commonly reported complications include balloon intolerance requiring early removal, gastric erosions, gastric

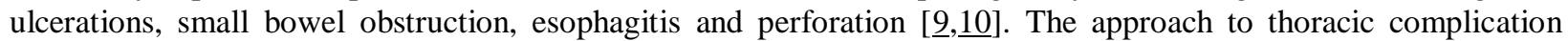
follows the basic scheme of making clinical assessment by proper history and physical examination to detect the basis and nature of the complications. The differential diagnosis spam from simple pleural effusion which can be a self-limiting reactionary one to a life threatening sever sepsis secondary to esophageal perforation and mediastinitis which carries high morbidity and mortality $[\underline{11}, \underline{12}, \underline{13}]$. Rarely, thoracic complications that requiring surgical intervention have been reported. As in our case which demonstrated several deviations from the standards. The first balloon was inflated within the distal esophageal part. This has led to esophageal perforation and migration of the balloon to the left pleural space. The attempt to deflate it was not complete. The patient was lucky since the balloon acted as a sealant to the esophageal perforation and resulted in a successful conservative measure. It is important to have high index of suspicion if the case does not go smoothly as usual to avoid major complications. The insertion and removal of this device have been always a challenge due to the lack of experience and training. In conclusion, in the era of increasing incidence of obesity and the varieties of modalities used to treat it, implementing standards of care is essential including proper training. High index of suspicion has to be on board for any new modality used to activate prompt effective management.

\section{Reference:-}

1. Choi HS, Chun HJ. Recent trends in endoscopic bariatric therapies. Clinical endoscopy. 2017 Jan;50(1):11.

2. Sallet JA, Marchesini JB, Paiva DS, Komoto K, Pizani CE, Ribeiro ML, Miguel P, Ferraz ÁM, Sallet PC. Brazilian multicenter study of the intragastric balloon. Obesity surgery. 2004 Aug 1;14(7):991-8.

3. Genco A, Bruni T, Doldi SB, Forestieri P, Marino M, Busetto L, Giardiello C, Angrisani L, Pecchioli L, Stornelli P, Puglisi F. BioEnterics intragastric balloon: the Italian experience with 2,515 patients. Obesity surgery. 2005 Sep 1;15(8):1161-4.

4. DeNicola E, Aburizaiza OS, Siddique A, Khwaja H, Carpenter DO. Obesity and public health in the Kingdom of Saudi Arabia. Reviews on environmental health. 2015 Aug 1;30(3):191-205.

5. Al-Nuaim AR. Population-based epidemiological study of the prevalence of overweight and obesity in Saudi Arabia, regional variation. Annals of Saudi medicine. 1997 Mar;17(2):195-9.

6. Dayyeh BK, Kumar N, Edmundowicz SA, Jonnalagadda S, Larsen M, Sullivan S, Thompson CC, Banerjee S. ASGE Bariatric Endoscopy Task Force systematic review and meta-analysis assessing the ASGE PIVI thresholds for adopting endoscopic bariatric therapies. Gastrointestinal endoscopy. 2015 Sep 1;82(3):425-38.

7. Ruiz D, Vranas K, Robinson DA, Salvatore L, Turner JW, Addasi T. Esophageal perforation after gastric balloon extraction. Obesity surgery. 2009 Feb 1;19(2):257-60.

8. Al-Momen A, El-Mogy I. Intragastric balloon for obesity: a retrospective evaluation of tolerance and efficacy. Obesity surgery. 2005 Jan 1;15(1):101-5.

9. Mathus-Vliegen EM, Tytgat GN. Intragastric balloons for morbid obesity: results, patient tolerance and balloon life span. British Journal of Surgery. 1990 Jan;77(1):76-9.

10. Geliebter A, Melton PM, McCray RS, Gage D, Heymsfield SB, Abiri M, Hashim SA. Clinical trial of siliconerubber gastric balloon to treat obesity. Int J Obes. 1991 Apr 1;15(4):259-66.

11. Kiernan PD, Sheridan MJ, Elster E, Rhee J, Collazo L, Byrne WD, Fulcher T, Hettrick V, Vaughan B, Graling P. Thoracic esophageal perforations. Southern medical journal. 2003 Feb 1;96(2):158-64.

12. Gupta NM, Kaman L. Personal management of 57 consecutive patients with esophageal perforation. The American journal of surgery. 2004 Jan 1;187(1):58-63.

13. Zumbro GL, Anstadt MP, Mawulawde K, Bhimji S. Surgical management of esophageal perforation: role of esophageal conservation in delayed perforation. The American Surgeon. 2002;68(1):36. 